\title{
PRK in patients with a keratoconic topography picture. The concept of a physiological 'displaced apex syndrome'
}

\author{
Stephen J Doyle, Eamonn Hynes, Shehzad Naroo, Sunil Shah
}

\begin{abstract}
Aims/Background-Keratoconus is generally held to be an absolute contraindication for photorefractive keratectomy (PRK). Corneas with inferior steepening on corneal topography are widely thought to have subclinical keratoconus. We were not convinced that this is always the case, as there seems to be a group of patients with a stable inferior steepening pattern on topography who show no other characteristics of clinical keratoconus. We thus decided to offer PRK to some of these patients under strictly defined criteria.

Method-Four myopic patients with a topography pattern of inferior steepening were submitted to PRK. They were selected on the basis of being aged over 35 , with a stable refraction, no slit-lamp signs of keratoconus, and a corrected vision of not less than $6 / 7(0.9)$ with a spherical spectacle correction. They gave fully informed consent that this was an experimental procedure.
\end{abstract}

Results-The refractive results at 6 months after operation were within the range one would expect for PRK on corneas with a regular 'bow-tie' topography and similar level of myopia. No unusual problems were encountered.

Conclusion-We feel that the corneal topography pattern of inferior steepening is not always a contraindication for PRK. The concept of a physiological 'displaced apex syndrome' is discussed and illustrated by corneal topography in different positions of gaze.

(Br f Ophthalmol 1996; 80: 25-28)

Corneal topography has become widespread in the past few years and has helped to define normal and abnormal corneal shapes. ${ }^{1-3}$ In photorefractive keratectomy (PRK) practice it is normal to do both pre- and postoperative topography, and it is not unusual to see the inferior steepening pattern seen in patients with clinical keratoconus. ${ }^{4-7}$ Until recently, we have regarded this as an absolute contraindication to PRK as it is commonly thought that this represents subclinical keratoconus. ${ }^{8}$ We were not convinced that this was always the case, as there seems to be a.group of patients with an inferior steepening pattern on topography who show no other characteristics of clinical keratoconus. We thus decided to offer PRK to some of these patients under strictly defined criteria.

\section{Materials and method}

Between June and December 1994 we performed PRK on 702 eyes of 702 patients with a Summit Excimed UV2000 laser (Summit Technology Inc, Waltham, MA, USA) with a $5 \mathrm{~mm}$ beam size. Eight patients had a clear topographic picture of inferior steepening $(1 \cdot 0 \%)$. We limited our client base for treatment to those with a cylinder of $1.00 \mathrm{D}$ or less as this laser does not treat astigmatism.

Corneal topography was performed pre- and postoperatively with the EyeSys corneal analysis system. Topography was performed in the normal way along the visual axis, and also with the patient looking upwards one or two rings on the videokeratoscope for patients who had inferior steepening.

Four patients with a corneal topography pattern of inferior steepening were submitted to PRK. They were chosen on the basis of the criteria shown in Table 1.

The corneal epithelium was removed manually using a Beaver blade. Pilocarpine $1 \%$ or $2 \%$ and diclofenac (Voltarol) were instilled 20 minutes preoperatively. PRK was done in the normal manner, with the patients fixating on the fixation light within the laser. A $5 \mathrm{~mm}$ treatment zone was used for all the patients. Immediately after the procedure, diclofenac and chloramphenicol ointment were instilled. Chloramphenicol ointment were used four times daily for the first week and steroid drops only used if it was felt that regression was occurring - that is, with the Summit laser we would expect the refraction to still be hypermetropic at 6 weeks, so if the refraction was plano or minus at the 6 week check, then fluorometholone eyedrops were given, four times daily for 1 month, tailing off over 2-3 months. The only patient needing steroids was patient 3, who was given fluorometholone from weeks 6 to 12 postoperatively.

The patients' personal details and preoperative refractions are shown in Table 2

All four patients showed bilateral inferior steepening in their corneal topography with a

\section{Table 1 Patient selection criteria for PRK}

1 Aged 35 years or over

A stable refraction over at least the preceding year Good preoperative vision of not less than 6/7 with a spherical spectacle refraction

4 No slit-lamp signs of keratoconus (that is, stromal thinning, Fleischer's ring, Vogt's striae, or anterior stromal thinning,

5 No other

No other risk factors for keratoconus such as a family history of the disease, an atopic diathesis, or a habit of eye rubbing

6 Informed written consent that this was an experimental procedure 
Table 2 Preoperative details

\begin{tabular}{|c|c|c|c|c|}
\hline & \multicolumn{4}{|l|}{ Patient } \\
\hline & 1 & 2 & 3 & 4 \\
\hline $\begin{array}{l}\text { Age } \\
\text { Sex } \\
\text { Sphere } \\
\text { Cylinder } \\
\text { Axis } \\
\text { Visual acuity } \\
\text { Best vision sphere } \\
\text { Acuity with best } \\
\text { vision sphere }\end{array}$ & $\begin{array}{l}42 \\
F \\
-2 \cdot 50 \\
-0 \cdot 75 \\
115 \\
6 / 5 \\
-3 \cdot 00 \\
6 / 5\end{array}$ & $\begin{array}{l}40 \\
F \\
-4 \cdot 00 \\
-0 \cdot 50 \\
45 \\
6 / 7 \\
-4 \cdot 00 \\
6 / 7\end{array}$ & $\begin{array}{c}38 \\
M \\
-5 \cdot 25 \\
-0 \cdot 25 \\
150 \\
6 / 6 \\
-5 \cdot 25 \\
6 / 6\end{array}$ & $\begin{array}{c}35 \\
M \\
-3 \cdot 50 \\
-0 \cdot 75 \\
60 \\
6 / 6 \\
-4 \cdot 00 \\
6 / 7\end{array}$ \\
\hline vision sphere & $6 / 5$ & $6 / 7$ & $6 / 6$ & $6 / 7$ \\
\hline
\end{tabular}

mirror image pattern between right and left eyes.

We also present here two examples of patients seen in the cornea clinic of Manchester Royal Eye Hospital with stable inferior steepening on topography:

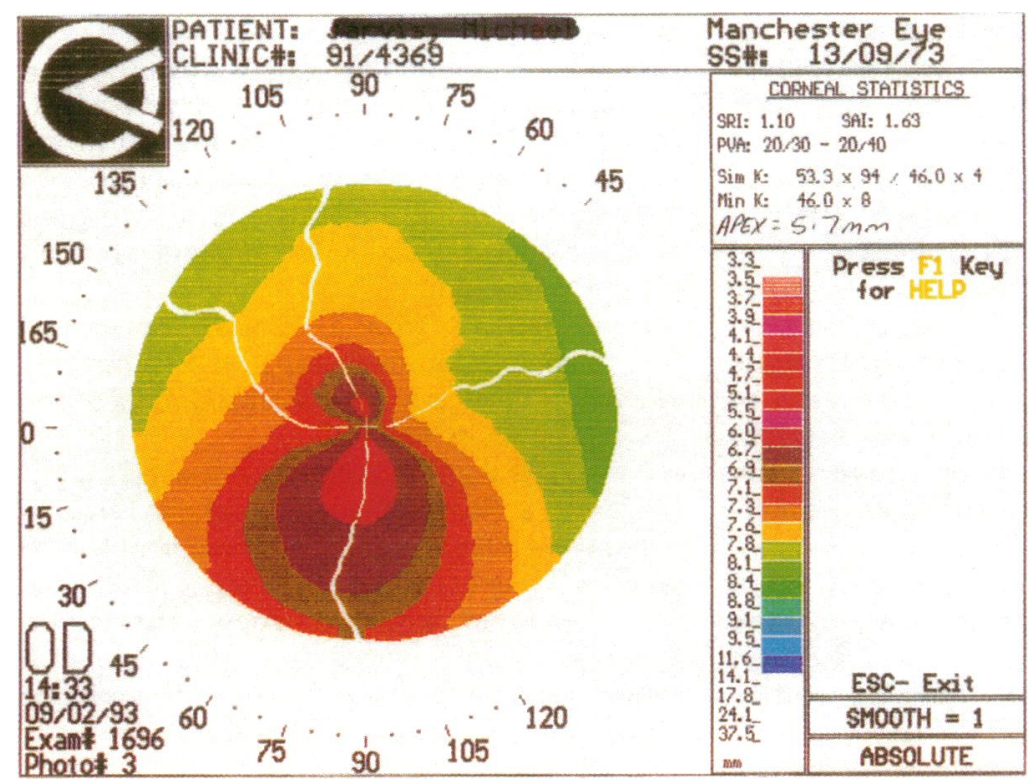

Figure 1 Patient 1 (see text). Refraction right eye aged 17: $+1 \cdot 0 /+0 \cdot 75 \times 75$. Refraction right eye aged 20: $+0 \cdot 75 /+0 \cdot 75 \times 75$ (6/5 acuity). Sim $K$ shows $7 \cdot 3 \mathrm{D}$ of corneal astigmatism (left eye is plano/ $+0.5 \times 120$ (6/6 acuity). Corneal topography unchanged over 3 years.

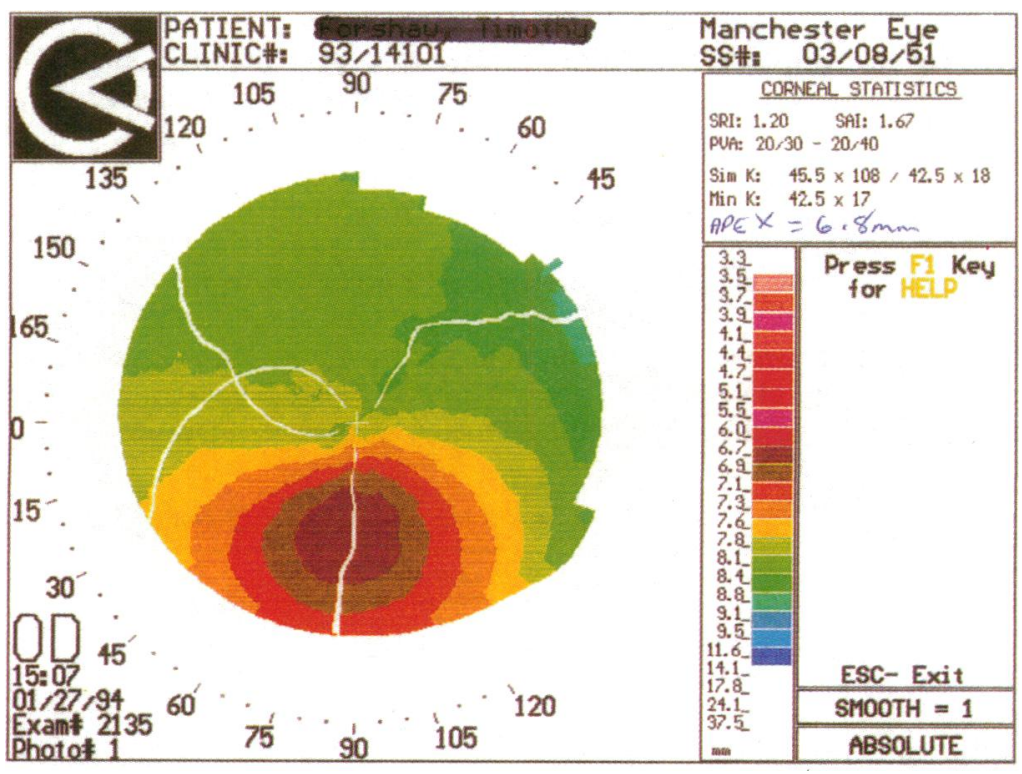

Figure 2 Topography of patient 2 (see text). Aged 42, 6/6 vision unaided all his life. Visited optician for glaucoma screening. Refraction right eye; plano/ $+0 \cdot 75 \times 90(6 / 5)$. Refraction left eye: $-0 \cdot 25 /+1 \cdot 00 \times 170(6 / 5)$. Sim K shows $3 D$ of corneal astigmatism. Corneal topography unchanged 1 year later.
Table 3 Postoperative results

\begin{tabular}{|c|c|c|c|c|}
\hline & \multicolumn{4}{|l|}{ Patient } \\
\hline & 1 & 2 & 3 & 4 \\
\hline $\begin{array}{l}\text { Best vision sphere } \\
\text { Acuity with BVS } \\
\text { BVD adjusted (14 mm) } \\
\text { Laser set } \\
\text { Weeks postoperative } \\
\text { Sphere } \\
\text { Cylinder } \\
\text { Axis } \\
\text { Unaided vision } \\
\text { Corrected vision } \\
\text { Haze (1-4) } \\
\text { Steroids used }\end{array}$ & $\begin{array}{c}-3 \cdot 00 \\
6 / 5 \\
-2 \cdot 88 \\
-2 \cdot 70 \\
26 \\
0 \\
-0 \cdot 25 \\
130 \\
6 / 5 \\
6 / 5 \\
1 \\
\text { None }\end{array}$ & $\begin{array}{c}-4 \cdot 00 \\
6 / 7 \\
-3 \cdot 79 \\
-3 \cdot 60 \\
24 \\
0 \cdot 50 \\
-0 \cdot 75 \\
50 \\
6 / 9 \\
6 / 7 \\
1 \\
\text { None }\end{array}$ & $\begin{array}{c}-5 \cdot 25 \\
6 / 6 \\
-4 \cdot 89 \\
-4 \cdot 70 \\
25 \\
-0 \cdot 50 \\
-0 \cdot 25 \\
145 \\
6 / 12 \\
6 / 7 \\
2 \\
\text { FML }\end{array}$ & $\begin{array}{c}-4 \cdot 00 \\
6 / 7 \\
-3 \cdot 79 \\
-3 \cdot 80 \\
37 \\
-0 \cdot 25 \\
-0 \cdot 50 \\
75 \\
6 / 9 \\
6 / 6 \\
1 \\
\text { None }\end{array}$ \\
\hline
\end{tabular}

$\mathrm{BVS}=$ best vision sphere $\mathbf{B V D}=$ back vertex distance; $\mathrm{FML}=$ fluorometholone.

\section{EXAMPLE 1}

A 20-year-old student was referred by his optometrist as a possible keratoconic patient because of a swirling retinoscopy reflex when aged 17. His slightly hypermetropic refraction and his corneal topography have remained unchanged during the 3 years we have been observing him (see Fig 1). He is neither atopic nor an eye rubber, has never worn contact lenses, and has no family history of myopia or astigmatism. Note that, despite $7 \cdot 3 \mathrm{D}$ of corneal astigmatism, he only needs $0.75 \mathrm{D}$ optically.

EXAMPLE 2

A 42-year-old man who has had 6/6 unaided vision all his life. He was seen by an optometrist for glaucoma screening and was again noted to have a swirling retinoscopy reflex. His topography and refraction are shown in Figure 2. His refraction and topography are completely unchanged 1 year later. Despite having $3 \mathrm{D}$ of corneal astigmatism, his optical cylinders are less than $1 \mathrm{D}$.

Figure 3 show the same patient as in Figure 1 but with his topography performed with him looking upwards two rings while performing videokeratoscopy. Note the conversion from inferior steepening to the 'bow-tie' pattern of regular astigmatism.

\section{Results}

The refractive results are shown in Table 3.

Patient 2 had some problems with night halos for a few weeks but seems to have adapted and now does not notice them at all. Patient 3 has night halos as he has very large pupils. (We only used a $5 \mathrm{~mm}$ beam size on these patients.) Patient 3 also has some loss of contrast sensitivity owing to subepithelial haze formation which is slowly clearing.

The topography of patient 1 after treatment of her right eye is shown in Figure 4 along with the untreated eye, which is enantiomorphic and almost exactly similar to the preoperative appearance of the right eye.

\section{Discussion}

We became interested in performing PRK on people with a 'keratoconic' pattern of inferior corneal steepening from the following observations. 


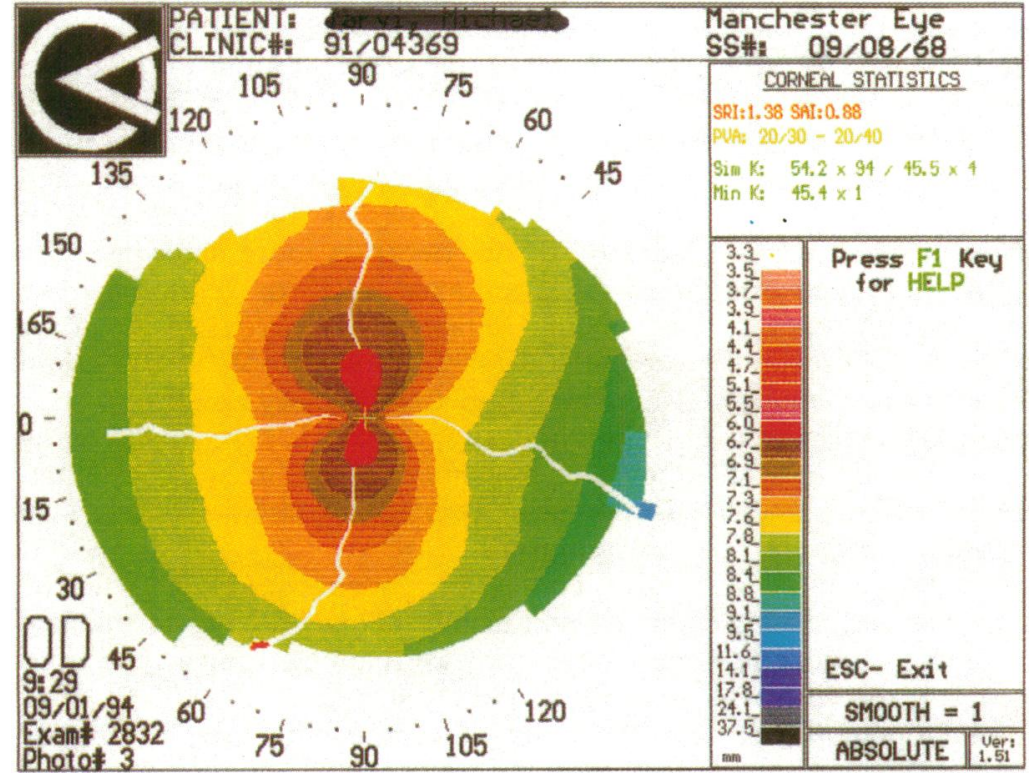

Figure 3 Patient shown in Figure 1 but with his topography done with the patient looking upwards two rings while performing videokeratoscopy. Note the conversion from inferior steepening to the 'bow-tie' pattern of regular astigmatism.

Some people who have what would be classed as subclinical keratoconus on corneal topography give a history of a stable refraction for many years. Keratoconus is mostly a disease of the late teens and early twenties and very rarely progresses beyond the age of $30 .^{9}$ The average age of presentation of the 276 keratoconics to date on the Manchester Royal Eye Hospital data base is 22 years. Patients do present over the age of 30 but, on taking their clinical histories, invariably have had the disease for some years. Some of the so called subclinical keratoconics have no abnormality other than an atypical topography pattern and, but for this test, would not be picked up at all. Two such examples are those illustrated above.

This made us wonder whether these and similar patients are just physiological variants. We have hence coined the term 'displaced apex syndrome' for them as we have no biochemical/genetic test for keratoconus to distinguish between pathological and physiological. We use this term to cover both subclinical keratoconics and some we think may have no abnormality other than an inferiorly displaced corneal apex.

Dingeldein and $\mathrm{Klyce}^{1}$ found, in 44 eyes of 22 emmetropic patients, that the area of greatest power was predominantly temporal to fixation in $27 \%$ of eyes, inferior to fixation in $11 \%$, and superior to fixation in $9 \%$. In the remaining $52 \%$ it was distributed evenly around the central unanalysed zone.
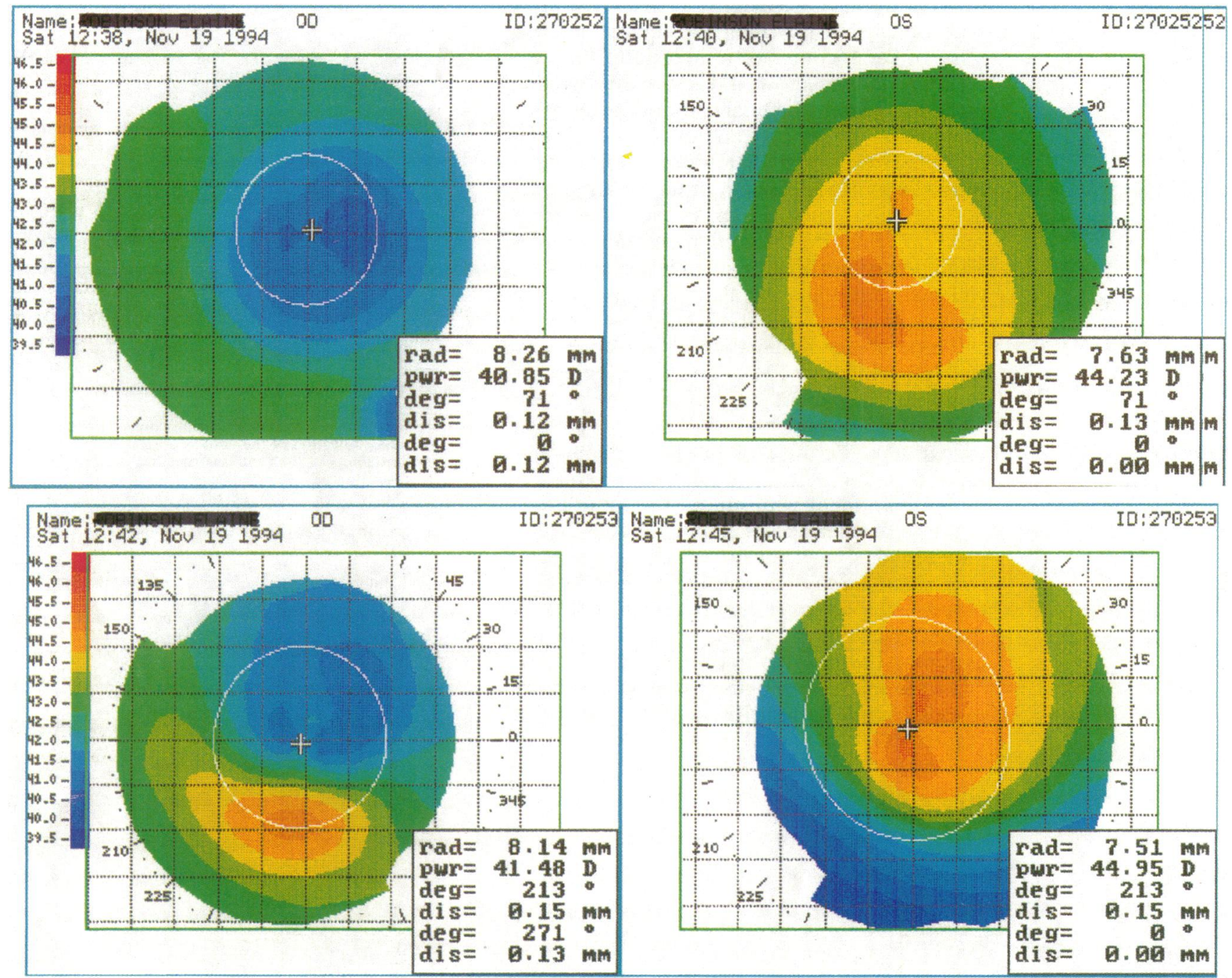

Figure 4 Top: Topography pictures of treated right eye and untreated enantiomorphic left eye of patient 1. Bottom: Same eyes but topography done with the patient fixating two rings up on the videokeratoscope. Note the inferior steepening of the right eye and the conversion to a 'bow-tie' pattern on the left. 
Edmund ${ }^{10}$ found the apex to be on average $0.48 \mathrm{~mm}$ temporal to the line of sight and $0.57 \mathrm{~mm}$ superior. Other investigators ${ }^{11} 12$ have found that the apex is commonly located temporal to the line of sight with no significant trend in the vertical meridian.

If a person with keratoconus or a keratoconic pattern on topography looks upwards one or two rings while undergoing corneal topography, then the typical keratoconic inferior steepening changes into the 'bow-tie' pattern of regular astigmatism, as the displaced apex becomes axial. This is especially true of the mild keratoconics where there is no corneal ectasia (see Figs 1 and 2). Hubbe and Foulks ${ }^{13}$ have used the term 'pseudokeratoconus' to mean cases where non-axial fixation during topography leads to a falsely keratoconic pattern on topography. However, the patients we describe here have abnormal topography on axial fixation and are hence a different group.

Mortensen and Ohrstrom ${ }^{14}$ have treated keratoconics with PRK who would otherwise have penetrating keratoplasty. The results were variable but the PRK did not lead to a progression or acceleration of the keratoconus. This was our major fear, in that lasering such corneas might lead to a progression of the disease or other abnormal reactions. We have no way of telling at present whether the patients we have designated as displaced apex syndrome are a physiological variant, a forme fruste of keratoconus, or a mixture of the two. Neither do we know if keratoconus is one disease or merely the final common pathway of a number of genetic and/or environmental factors. However, if PRK does not lead to a progression of the disease, or any other abnormal reaction (such as an abnormal scarring reaction), then the distinction between the two groups may not matter in practice and what will matter more is the algorithm used by the lasering to correct the irregular corneal shape.

Three of our four patients have done very well following their PRK. The slight regression of the fourth patient has followed the pattern seen in other patients with regular corneal topography. Because of his night halos and slight regression, he could have a zone enlargement/retreatment with one of the more modern lasers when he is stable. None of the patients has shown any further changes suggestive of activation of an underlying keratoconic process. However, we clearly need to follow all these patients over a longer time period before assuming that they do not behave abnormally.

As the irregular astigmatism becomes more marked, then axial PRK, which imposes a regular spherical optical solution onto an irreg- ular non-spherical cornea, becomes a more and more unsatisfactory solution to the optics of these eyes. The treatment of clinical keratoconus from mild to severe progresses from glasses to gas permeable contact lenses and finally to keratoplasty as the disease worsens and the cornea becomes more deformed. We would expect axial PRK or photorefractive astigmatic keratectomy (PARK) as it is presently available to work only in the group where glasses give satisfactory vision.

Gibralter and Trokel ${ }^{15}$ have made early moves to treat more severe irregular astigmatism by using overlapping circular zones. Two other approaches are:

(1) To treat the patient with PARK while he fixates non-axially. This presents formidable problems, not least that of getting a good nonaxial refraction/retinoscopy.

(2) Tying the corneal topography directly into the laser software to sculpt the corneal profile accordingly. We think that this latter approach will be the better long term solution and is looked upon by many as the 'Holy Grail' of corneal laser surgery.

None of the authors has any commercial or proprietary interest in either the Summit Corporation or in the EyeSys Corporation.

Our thanks to Mr AEA Ridgway for his encouragement, for
Ont Our thanks to Mr AEA Ridgway for his encouragement, for
the use of two of his patients as examples in this paper, and for help with the Manchester Royal Eye Hospital keratoconus data base.

1 Dingeldein SA, Klyce SD. The topography of normal corneas. Arch Ophthalmol 1989; 107: 512-8.

2 Wilson SE, Klyce SD. Quantitative descriptions of corneal topography. Arch Ophthalmol 1991; 109: 349-53.

3 Wilson SE, Klyce SD. Screening for corneal topographic abnormalities before refractive surgery. Ophthalmology 1994; 101: 147-52.

4 Maquire LJ, Bourne WM. Corneal topography of early keratoconus. Am $\mathcal{F}$ Ophthalmol 1989; 108: 107-12.

5 Maguire LJ, Lowry JC. Identifying progression of subclinical keratoconus by serial topography analysis. Am $\mathcal{F}$ Ophthalmol 1991; 112: 41-5.

6 Gonzalez V, McDonnell PJ. Computer-assisted corneal topography in parents of patients with keratoconus. Arch Ophthalmol 1992; 110: 1412-4.

7 Maeda N, Klyce SD, Smolek MK, Thompson HW. Automated keratoconus screening with corneal topo-
graphy analysis. Invest Ophthalmol Vis Sci 1994; 35: graphy an

8 Royal College of Ophthalmology. Guidelines for photorefractive keratectomy. April 1995

9 Manchester Royal Eye Hospital keratoconus database.

10 Edmund C. Location of the corneal apex and its influence on the stability of the central corneal curvature: a photokeratoscopy study. Am f Optom Physiol Opt 1987; 64: 846-52.

11 Tomlinson A, Schwartz C. The position of the corneal apex in the normal eye. Am $f$ Optom Physiol Opt 1979; 56: $236-40$.

12 Bonnet $R$, Cochet P. New method of topographical ophthalmometry - its theoretical and practical applications. Am f Optom Physiol Opt 1962; 39: 227-51.

13 Hubbe RE, Foulks GN. The effect of poor fixation on computer assisted topographic analysis - pseudokeratoconus. Ophthalmology 1994; 101: 1745-8.

14 Mortensen J, Ohrstrom A. Excimer laser phototherapeutic keratectomy for the treatment of keratoconus. $\mathcal{F}$ Refract Corneal Surg 1994; 10: 368-72.

15 Gibralter R, Trokel SL. Correction of irregular astigmatism with the excimer laser. Opthalmology 1994; 101: 1310-5. 